\title{
Disease-relevant autoantibodies in first episode schizophrenia
}

\author{
Michael S. Zandi - Sarosh R. Irani $\cdot$ Bethan Lang $\cdot$ Patrick Waters \\ Peter B. Jones $\cdot$ Peter McKenna $\cdot$ Alasdair J. Coles • Angela Vincent • \\ Belinda R. Lennox
}

Received: 15 June 2010/Revised: 27 September 2010/Accepted: 1 October 2010/Published online: 26 October 2010

(C) The Author(s) 2010. This article is published with open access at Springerlink.com

Dear Sirs,

Schizophrenia is a common, heterogenous and complex disorder with unknown aetiology [1]. There is established evidence for $N$-methyl-D-aspartate receptor (NMDAR) hypofunction [2] as a central component of the functional dysconnectivity that is the most accepted model for symptoms [3], and increasing evidence for potassium channel dysfunction [4]. Moreover, autoimmune mechanisms have been proposed, perhaps in subgroups of patients [5, 6]. In the last few years, antibodies to neuronal cell surface antigens have been identified in cases of autoimmune encephalitis that respond to immunotherapy [7, 8]. Over two-thirds of patients with NMDAR antibody encephalitis, and some with potassium channel antibody-

Electronic supplementary material The online version of this article (doi:10.1007/s00415-010-5788-9) contains supplementary material, which is available to authorized users.

M. S. Zandi · A. J. Coles

Neurology Unit, Department of Clinical Neurosciences, University of Cambridge, Addenbrooke's Hospital,

Cambridge CB2 0QQ, UK

S. R. Irani - B. Lang - P. Waters · A. Vincent

Neurosciences Group, Department of Clinical Neurology, University of Oxford, John Radcliffe Hospital,

Oxford OX3 9DU, UK

P. B. Jones - B. R. Lennox $(\bowtie)$

Department of Psychiatry, University of Cambridge, Herchel Smith Building for Brain and Mind Sciences, Cambridge Biomedical Campus, Cambridge CB2 0SZ, UK e-mail: bl224@cam.ac.uk

P. McKenna

Benito Menni Complex Assistencial en Salut Mental, CIBERSAM, Barcelona, Spain associated limbic encephalitis, have prominent psychiatric symptoms, or may present to psychiatric services in the first instance $[7,9,10]$. The psychiatric symptoms are those seen in schizophrenia including delusions, hallucinations, and catatonic movement disorder. There is good evidence for specificity and pathogenicity of these antibodies, with absence in large numbers of healthy individuals and those with other neurological diseases $[9,11,12]$. However, there have been no cases of NMDAR or potassium channel antibodies identified in patients with purely psychiatric disorders. We hypothesized that these antibodies would be present in a proportion of patients with early schizophrenia, in the absence of overt seizures, movement disorders, or other neurological signs.

Serum was obtained prospectively from a cohort ( $n=46)$ of patients at first presentation of psychosis to an epidemiologically principled early intervention for psychosis service (http://www.cameo.nhs.uk), which provides 3 years of treatment and follow up when possible. We retrospectively measured NMDAR antibodies using a cell based assay and subjective visual scoring system [9]. We identified antibodies to components of potassium channel complexes (VGKCs) by radioimmunoassay [8]. The sera were tested blind to diagnostic status. Patients with positive results were retrospectively interviewed and extensively investigated. Full clinical details are given in the Table and supplementary information.

Patients 1 and 2 had NMDAR antibodies, [patient 1: score 2, (range 0-4, normal 0-0.5, Fig. 1); patient 2: score 1]. Patient 1 was unwell for 6 months before recovering; he was well and antibody negative at 3 years. Patient 2 has had a protracted course; antibodies remained repeatedly positive at 24-35 months follow up, but were then negative at 36 months. Patient 3 had VGKC antibodies $(1,435 \mathrm{pM}$; normal $<100$ ), was unwell for 6 months before recovering, but has subsequently relapsed after 1 year and has now 


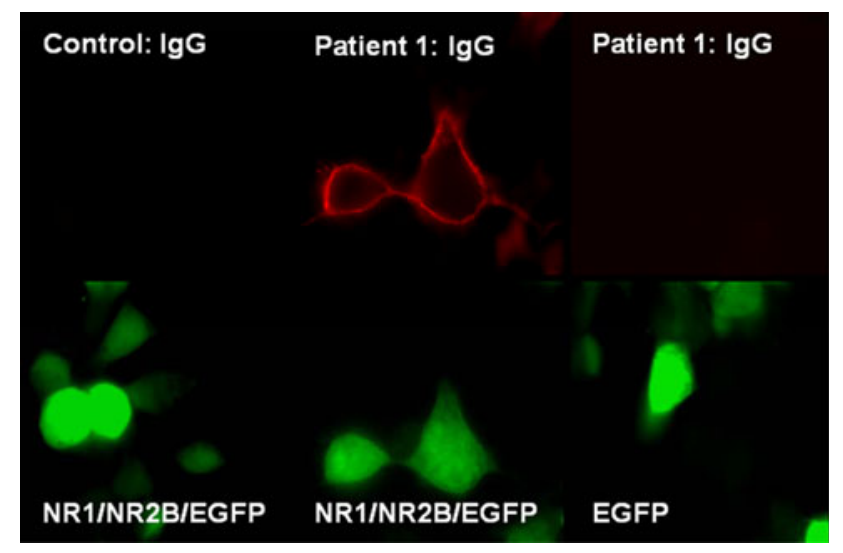

Fig. 1 HEK cells co-transfected with NR1, NR2B and EGFP cDNA or transfected with EGFP cDNA alone. Serum of patient 1 bound to the surface of unpermeabilised cells transfected with NMDARs, but not EGFP alone. Healthy controls (Control) showed no binding

been lost to follow up. There were no clinical features to differentiate these cases from other cases of psychosis in Cameo (Table 1), even in retrospect, and the autoantibody positive cases fulfilled criteria for DSM-IV schizophrenia. No patient had physical neurological symptoms or signs.

A further patient, patient 4 , with first episode psychosis identified after the prospective cohort, had NMDAR antibodies (score 1.5). He was unwell for 4 months, partially responsive and then relapsing despite treatment with antipsychotics. To reduce the levels of NMDAR antibodies he received plasmapheresis and made a significant clinical improvement 3 weeks later, improving further with prednisolone. He remains clinically and functionally improved at 7 month follow up, on no antipsychotic medication. This is the first case description, to our knowledge, of a patient with NMDAR antibodies and a purely psychiatric presentation responding to immunotherapy.

These preliminary data show that some patients with schizophrenia have potentially pathogenic autoantibodies to relevant membrane proteins. Three of the patients had NMDAR antibodies, which have been shown to reduce NMDAR clusters in vivo [12], which mirrors that seen in models of schizophrenia [13]. All of our antibody positive cases $(6.5 \%$ of 46$)$ fulfilled DSMIV criteria for schizophrenia and the patients were tested early in the course of their illness. None of the chronic schizophrenia controls in our large case series had NMDAR antibodies [9], but this could be because NMDAR and VGKC antibodies spontaneously drop with time ([14]; SRI, AV unpublished data); this suggests a critical early period of illness for detection and treatment. We did not measure antibody in CSF, and future prospective systematic studies of antibody in paired serum and CSF will be informative.

The 46 patients in the Cameo cohort were given DSMIV diagnoses a year after intake to the service. Of these,

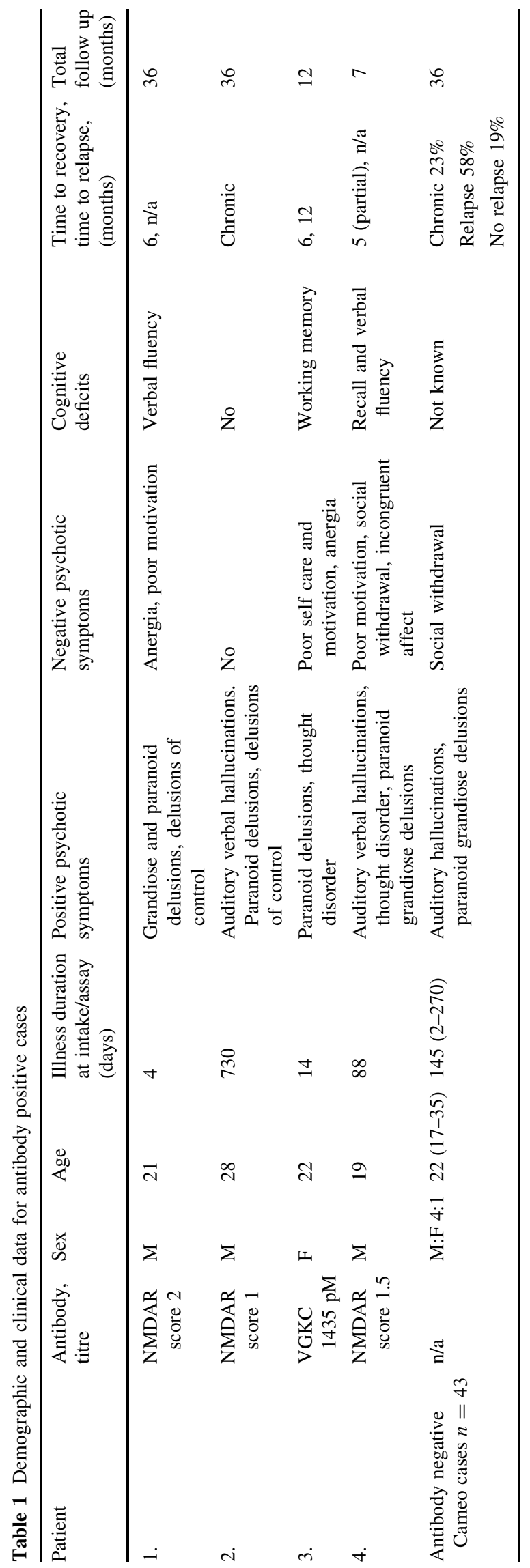


$63 \%$ had a diagnosis of schizophrenia. Other psychotic diagnoses were psychosis not otherwise specified $(15 \%)$, bipolar affective disorder $(13 \%)$, schizoaffective disorder (4\%), major depression with psychosis (2\%) and delusional disorder $(2 \%)$. It is therefore possible that the proportion of cases with diagnoses of schizophrenia that have specific antibodies is higher than the proportion described here. However, there is significant diagnostic instability in patients with early psychosis, due to the threshold of chronicity required for a diagnosis of schizophrenia. There is also increasing evidence of shared heritability between the psychotic disorders and consequently a move away from the use of categorical diagnoses in those with psychotic disorders.

There is a need for a systematic screen of available neuronal surface antigens in first episode psychosis and schizophrenia to characterise the true prevalence of these antibodies among different population groups, with implications for diagnosis, prognosis and treatment.

Acknowledgments This work was supported by the National Institute for Health Research (NIHR) CLAHRC for Cambridgeshire and Peterborough, CIBERSAM, Spain and the Oxford Biomedical Research Centre. MSZ holds an Eastern Region Neurosciences Training Fellowship. SRI held an NIHR clinical training fellowship. We also wish to acknowledge Professor F. Anne Stephenson, at the School of Pharmacy, University of London for her help in developing the NMDAR assay. We would like to thank Prof D Beeson and Ms S Maxwell for their assistance with the cloning and expression of NMDAR subunits, Dr F Winton as clinical referrer and Dr J Stochl for help with the Cameo demographic data.

Conflict of interest $\mathrm{MZ}$ and PW report no disclosures. SRI, PBJ and BLe receive support from the NIHR. AJC reports receiving consulting fees, lecture fees, and grant support from Genzyme. PMcK is supported by CIBERSAM, Spain. AV receives royalties from Athena Diagnostics, and the department of Clinical Neurology in Oxford receives royalties and payments for antibody assays.

Open Access This article is distributed under the terms of the Creative Commons Attribution Noncommercial License which permits any noncommercial use, distribution, and reproduction in any medium, provided the original author(s) and source are credited.

\section{References}

1. Harrison PJ, Weinberger DR (2005) Schizophrenia genes, gene expression, and neuropathology: on the matter of their convergence. Mol Psychiatry 10:40-68

2. Javitt DC (2007) Glutamate and schizophrenia: phencyclidine, $N$ methyl-D-aspartate receptors, and dopamine-glutamate interactions. Int Rev Neurobiol 78:69-108

3. Stephan KE, Friston KJ, Frith CD (2009) Dysconnection in schizophrenia: from abnormal synaptic plasticity to failures of self-monitoring. Schizophr Bull 35:509-527

4. Huffaker SJ, Chen J, Nicodemus KK, Sambataro F, Yang F, Mattay V et al (2009) A primate-specific, brain isoform of $\mathrm{KCNH} 2$ affects cortical physiology, cognition, neuronal repolarization and risk of schizophrenia. Nat Med 15:509-518

5. Jones AL, Mowry BJ, Pender MP, Greer JM (2005) Immune dysregulation and self-reactivity in schizophrenia: do some cases of schizophrenia have an autoimmune basis? Immunol Cell Biol 83:9-17

6. Stefansson H, Ophoff RA, Steinberg S, Andreassen OA, Cichon S, Rujescu D et al (2009) Common variants conferring risk of schizophrenia. Nature 460:744-747

7. Dalmau J, Gleichman AJ, Hughes EG, Rossi JE, Peng X, Lai M et al (2008) Anti-NMDA-receptor encephalitis: case series and analysis of the effects of antibodies. Lancet Neurol 7:1091-1098

8. Vincent A, Buckley C, Schott JM, Baker I, Dewar BK, Detert N et al (2004) Potassium channel antibody-associated encephalopathy: a potentially immunotherapy-responsive form of limbic encephalitis. Brain 127:701-712

9. Irani SR, Bera K, Waters P, Zuliani L, Maxwell S, Zandi MS et al (2010) $N$-methyl-D-aspartate antibody encephalitis: temporal progression of clinical and paraclinical observations in a predominantly non-paraneoplastic disorder of both sexes. Brain 133:1655-1667

10. Parthasarathi UD, Harrower T, Tempest M, Hodges JR, Walsh C, McKenna PJ et al (2006) Psychiatric presentation of voltagegated potassium channel antibody-associated encephalopathy. Case report. Br J Psychiatry 189:182-183

11. Dalmau J, Tuzun E, Wu HY, Masjuan J, Rossi JE, Voloschin A et al (2007) Paraneoplastic anti- $N$-methyl-D-aspartate receptor encephalitis associated with ovarian teratoma. Ann Neurol 61:25-36

12. Hughes EG, Peng X, Gleichman AJ, Lai M, Zhou L, Tsou R et al (2010) Cellular and synaptic mechanisms of anti-NMDA receptor encephalitis. J Neurosci 30:5866-5875

13. Belforte JE, Zsiros V, Sklar ER, Jiang Z, Yu G, Li Y et al (2010) Postnatal NMDA receptor ablation in corticolimbic interneurons confers schizophrenia-like phenotypes. Nat Neurosci 13:76-83

14. Buckley C, Oger J, Clover L, Tuzun E, Carpenter K, Jackson M et al (2001) Potassium channel antibodies in two patients with reversible limbic encephalitis. Ann Neurol 50:73-78 